\title{
Comparison of scalar and vector electrocardiographic diagnosis and localization of myocardial infarction
}

\author{
G. McNeill, D. Emslie-Smith, and K. G. Lowe \\ From the Department of Medicine, University of Dundee, Dundee
}

A prospective study was made of 80 patients during typical clinical episodes of acute myocardial infarction with biochemical and scalar electrocardiographic confirmation. Nine patients had bundle-branch block and 12 had had previous episodes of myocardial infarction. Serial electrocardiograms and vectorcardiograms were recorded during the first week in hospital. The most striking finding was that in more than half the cases there was disagreement between the electrocardiogram and vectorcardiogram in the localization of infarction. The earliest evidence of infarction in the electrocardiogram is often restricted to ST and T changes though in the corresponding vectorcardiograms evidence of infarction may be present in the $Q R S$ loop. In those cases in which both electrocardiogram and vectorcardiogram show $Q R S$ abnormalities these are frequently detected earlier in the vectorcardiogram, but the converse is rare.

Criteria for the scalar and vector electrocardiographic diagnosis and localization of myocardial infarction have been proposed and improved upon over many years. Their correlation with each other and with subsequent necropsy findings have led some authors (Gunnar et al., 1967) to claim that the spatial vectorcardiogram, and others (Simonson et al., 1966) that the scalar electrocardiogram provides the better diagnostic information. It seems to be impossible to devise perfect diagnostic criteria for either the electrocardiogram or vectorcardiogram and an increased diagnostic sensitivity of any proposed criteria is offset by a concomitant loss of specificity with quite high rates of false-positive diagnosis (Eddleman and Pipberger, 197I). The electrocardiogram is particularly useful for studying changes in the ST segment and $T$ wave, whereas ST and $T$ vectors are not easily analysed in the vectorcardiogram. On the other hand, electrical events during ventricular depolarization are often more clearly demonstrated in the vectorcardiogram than in the electrocardiogram. Moreover, the natural history of coronary artery disease and the morbid anatomical accompaniments are so varied and complex that in clinical practice we are not always presented with clear-cut cases of myocardial infarction precisely limited to one area of the left ventricle. Rather do we see a spectrum of disease, and patients may present with infarction that is single or mul-

Received 27 August 1974. tiple, old or new, localized or diffuse, and often associated with other cardiac abnormalities such as cor pulmonale, hypertensive heart disease, and disturbances of conduction.

Despite these facts, the computer-assisted analysis and interpretation of routine electrocardiograms, using programmes based on rigidly defined numerical criteria, is already in use, and there is insufficient awareness of the limitations of the practice. We therefore decided to study prospectively a consecutive series of patients with acute myocardial infarction and to compare the electrocardiogram with the vectorcardiogram according to selected but widely acceptable diagnostic criteria. We have also studied and compared the evolutionary changes in the electrocardiogram and vectorcardiogram by taking serial records during the acute clinical episodes.

\section{Vectorcardiographic diagnostic criteria}

The recognition of myocardial infarction from the electrocardiogram has been a universal daily practice for decades and does not require further comment here, but the recognition of infarction from the vectorcardiogram has been developed much more recently. In the cardiographic diagnosis of infarction it is customary to designate sites based on electrical rather than anatomical considerations (Walsh et al., 1962), and it is usual to distinguish the following: inferior, anteroseptal, anterolateral, 
and posterior (with variations according to different authors), singly or in combination. The criteria for the vectorcardiographic diagnosis of infarcts in these conventional sites are as follows.

\section{Inferior infarction}

Significant elevation of the early vectors (Io to $30 \mathrm{~ms}$ ) in the frontal and sagittal planes and clockwise rotation of the initial part of the QRS loop in the frontal plane are the chief features of inferior infarction (Milnor et al., 195I ; Scherlis and Grishman, 195I; Burch et al., I955; Young, Wolff, and Chatfield, 1956a; Sodi-Pallares, 1956; Burch et al., 1958; Howitt and Lawrie, 1960; Hugenholtz, Whipple, and Levine, 196Ib; Hugenholtz, Forkner, and Levine, 1961a; Tranchesi et al., 1961; Wolff et al., 1961; Walsh et al., 1962; Abramson, 1963; Hoffman, Taymor, and Gootnick, 1964; Gunnar et al., 1967).

The criteria we have selected (Gunnar et al., 1967) successfully predicted infarction in 92 per cent of the authors' cases and correctly localized the site when correlated with necropsy findings. On the other hand, the criteria were fulfilled in 32 per cent of patients with normal hearts.

\section{Anteroseptal infarction}

Criteria for the diagnosis of anteroseptal infarction have been largely based on the posterior direction of early vectors (10 to $30 \mathrm{~ms}$ ) in the horizontal plane (Scherlis and Grishman, I95 I Karlen, Wolff, and Young, 1956; Burch, Horan, and Cronvich, 1956; Burch et al., 1958; Howitt and Lawrie, 1960; Wolff et al., 196r; Hugenholtz et al., 1963; Simonson et al., 1966; Gunnar et al., 1967).

\section{Anterolateral infarction}

The chief criteria for the diagnosis of anterolateral infarction are the clockwise rotation of the initial forces and the posteriorly directed $20 \mathrm{~ms}$ vector in the horizontal plane, and counterclockwise rotation of the QRS loop in the frontal plane (Scherlis and Grisham, 1951; Burch et al., 1956, 1958; Howitt and Lawrie, 1960; Hugenholtz et al., 1961a, b; Wolff et al., 1961; Doucet, Walsh, and Massie, 1966; Gunnar et al., 1967).

\section{Posterior infarction}

Criteria for the diagnosis of posterior infarction depend on quantitative aspects of the anterior displacement of the QRS loop in the horizontal plane (Scherlis and Grishman, 195I; Elek et al., 1954; Jacobson et al., 1959; Rothfield et al., I959; Hugenholtz et al., 1961a, b; Wolff et al., I96r; Tranchesi et al., 196I; Walsh et al., 1962; Hoffman et al., 1965; Gunnar et al., 1967).

\section{$J$ vector and $T$ loop criteria}

Diagnostic features based on the direction and magnitude of the $\mathrm{J}$ vector and on the direction, shape, and route of inscription of the $T$ loop have been described by a number of authors (Cosby et al., 1955; Burch et al., 1955; Hoffman and Schack, 1956; Karni, 1956; Karlen et al., 1956; Young, Wolff and Karlen, 1956b; Sano et al., 1960; Tranchesi et al., 196I; Chou, Helm, and Lach, 1964). The J vector and $\mathrm{T}$ loop are difficult to study and the vectorcardiographic diagnosis of infarction is usually based on abnormalities of the QRS loop.

\section{Diagnosis of myocardial infarction in presence of ventricular hypertrophy and bundle-branch block}

Complicating cardiac conditions can make the diagnosis and localization of myocardial infarction more difficult. These include left ventricular hypertrophy (Burch et al., 1955; Wolff, 1955; Young et al., 1956b; Karlen et al., 1956; Milnor, 1957; Hugenholtz et al., 196rb, 1963; Simonson et al., 1966), and right ventricular hypertrophy (Hugenholtz et al., I961a; Rothfield et al., 196I; Tranchesi et al., 196I; Gunnar et al., 1967). Right bundlebranch block causes difficulty with the diagnosis of posterior infarction (Doucet et al., 1966; Simonson et al., 1966; Gunnar et al., 1967). It is often difficult to diagnose infarction in the presence of left bundlebranch block, but it may be possible in some cases, for example, of anterolateral infarction, and here the vectorcardiogram has some advantages over the electrocardiogram (Hugenholtz et al., 196Ib; Simonson et al., 1966).

\section{Case material}

Eighty men and women with clinical, biochemical, and scalar electrocardiographic evidence of acute myocardial infarction were investigated after their admission to the medical wards of the Dundee Royal Infirmary. Patients with severe shock or persistent cardiac arrhythmias were not included in the series. All had persisting retrosternal pain lasting more than 15 minutes. The series included cases with no evidence of previous cardiac disease and also patients with pre-existing disease such as angina pectoris, hypertension, and previous episodes of myocardial infarction. In all the cases with a history of previous infarction there was evidence of recent infarction on the scalar electrocardiogram.

\section{Methods}

\section{Biochemistry}

Serum glutamic oxaloacetic transaminase (SGOT) and 
hydroxybutyric dehydrogenase (HBD) levels were estimated routinely in the Clinical Chemistry Department by methods based on those of Reitman and Frankel (I957) and Elliot and Wilkinson (196I), respectively. In each case there was a significantly raised serum level of SGOT or HBD within 5 days of hospital admission.

\section{Electrocardiography}

Within 8 days of admission to hospital 4 serial scalar electrocardiograms and 4 serial vectorcardiograms were recorded. Corresponding cardiograms were performed within Io minutes of each other. The first cardiograms were performed within 30 hours of hospital admission and the second and third within the following 72 hours. The fourth and final cardiograms were performed on the seventh or eighth day after admission.

\section{Vectorcardiography}

We used the system of electrode placement devised by Frank (1956). A Sanborn vectorcardiograph was employed, with a storage oscilloscope and an ultraviolet polaroid camera. The horizontal, frontal, and right sagittal projections of the spatial QRS loop were photographed. Several QRS complexes were visualized to ensure that varying complexes, attributable to aberrant conduction or ectopic foci, were not present. If the projections of the $P$ and $T$ loops obscured the QRS loop they were erased from the oscilloscope so that undisturbed solitary QRS loops could be photographed. The inscription of the QRS loops was interrupted at $5 \mathrm{~ms}$ intervals. The deflection of the cathode ray on the oscilloscope could be altered allowing a deflection of I $\mathrm{cm}$ to be equivalent to $0.1,0.2,0.5$, or $\mathrm{r} .0 \mathrm{mV}$.

Although the patients were usually in a recumbent position and breathing quietly while the cardiograms were being taken, the presence of breathlessness, and its management by a more vertical posture, did not enable cardiograms to be taken in a precisely uniform posture and at a constant phase of respiration.

\section{Vectorcardiographic criteria}

Evidence of myocardial infarction was sought on the serial vectorcardiogram, employing the criteria for inferior, anteroseptal, anterolateral, and posterior infarction suggested by Gunnar and his colleagues in 1967.

The criteria for inferior infarction were:

I) Clockwise rotation in the frontal plane plus the maximum projection of the QRS vector in this plane situated between $270^{\circ}$ and $35^{\circ}$. In patients under 50 years of age, Gunnar stipulated that the maximum projection of the QRS vector should be situated between $270^{\circ}$ and $20^{\circ}$ in the frontal plane.

2) The 20 and $30 \mathrm{~ms}$ vectors directed superiorly in the frontal and sagittal planes.

If either criterion were fulfilled the diagnosis of infarction was made.

The criterion for anteroseptal infarction was posterior displacement of the $20 \mathrm{~ms}$ vector behind the frontal plane and the criterion for anterolateral infarction was clockwise rotation of the initial forces in the horizontal plane about the point of zero potential.
The criterion of posterior infarction was counterclockwise inscription in the horizontal plane in association with more than half the area of the QRS loop anterior to the point of zero potential.

\section{Scalar electrocardiography}

In each case criteria of either myocardial infarction (Myers, Klein, and Hiratzka, 1948a, I949a, b; Myers, Klein and Stofer, 1948b) or bundle-branch block (Hugenholtz et al., 196Ib; Simonson et al., 1966) were fulfilled on the standard 12 -lead scalar electrocardiogram.

Scalar criteria of inferior infarction were those of Myers et al. (1949a) which they had correlated with necropsy studies.

I) In aVF, a $Q$ wave exceeding $40 \mathrm{~ms}$ in duration.

2) In aVF, a QR complex of $0.5 \mathrm{mV}$ or more, when the $Q$ wave measures $30 \mathrm{~ms}$ or more from onset to nadir, and exceeds 25 per cent of the amplitude of the associated $\mathbf{R}$ wave.

3) Classical RS-T displacement (see below) in aVF. The criteria of anteroseptal infarction were those of Myers et al. (1948b).

I) The presence of a normal initial $R$ wave in lead $V I$ or in another lead from the right anterior chest wall (in this study, $V_{3} R$ ) plus replacement of the normal initial upright deflection in one or more of the three leads $V_{2}, V_{3}, V_{4}$ by a $Q S$ or an abnormal QR complex, and absence of a normal $Q$ wave from leads $V_{5}$, V6, and aVL and the standard limb leads.

The $Q$ wave of a $Q R$ complex was considered abnormal when the time interval from its onset to nadir exceeded $20 \mathrm{~ms}$ and when its amplitude was more than 25 per cent of the voltage of the succeeding $R$ wave. Myers and his colleagues (I948b) felt that such a $Q$ wave was only diagnostic of anteroseptal infarction if it was found in every cardiac cycle, otherwise it could be attributable to respiratory changes. In this series this stipulation was not enforced.

2) Classical RS-T displacement in $\mathrm{V}_{2}$ or $\mathrm{V}_{3}$ or $\mathrm{V}_{4}$.

If either criterion were fulfilled a diagnosis of anteroseptal infarction was made.

The criteria of anterolateral infarction (Myers et al., 1948a) were:

I) In leads $\mathrm{V}_{5}$ plus V6 and/or aVL an abnormal $\mathrm{QR}$ pattern characterized by a $Q$ wave of more than 20 $\mathrm{ms}$ in duration from onset to nadir and amounting to 25 per cent or more of the amplitude of the succeeding $R$ wave.

2) Classical RS-T displacement in $V_{5}$ plus V6 and/or aVL.

If either criterion were fulfilled a diagnosis of anterolateral infarction was made.

The criteria of posterior infarction were those of Myers et al. (1949b) for posterolateral infarction:

I) Large $R$ waves in leads $V I$, plus V2, plus or minus $V_{3}$ and $V_{4}$.

2) An RsR' pattern in VI, with large $R$ waves in $V_{2}$ plus $V_{3}$.

3) ST depression, plus peaked T waves in VI and V2. 
Myers made no attempt to quantify the size of significantly abnormal $\mathbf{R}$ waves in criteria $\mathbf{I}$ and 2.

'Classical RS-T displacement' was considered as ST elevation greater than $0.1 \mathrm{mV}$, followed by the return of ST to the isoelectric line associated with inversion of the $\mathrm{T}$ wave. Sudden inversion of the $\mathrm{T}$ wave, per se, was also considered to be evidence of infarction. In 1959 the World Health Organization reported that when these classical RS-T changes occurred the probability of myocardial infarction being present was almost 100 per cent.

The electrocardiographic and vectorcardiographic criteria outlined above were strictly observed, and, using them, comparisons were made between the evolving patterns of myocardial infarction on the scalar electrocardiograms and vectorcardiograms.

\section{Results}

The results of the comparisons first mentioned are shown in Tables 1,2 , and 3.
Of the 80 cases, I2 had a history and cardiographic evidence of previous infarction (Table 3 ). Nine had bundle-branch block ( 5 right and 4 left), and one of these, with right bundle-branch block, had both old and recent infarcts (Table 2). These 2 groups are considered separately.

\section{Patients with first episode of myocardial in- farction}

Sixty cases remained in which we could compare the localization of first infarction determined from the electrocardiogram and vectorcardiogram (Table I). According to the criteria we adopted the localization agreed in 28 cases but failed to do so in 32 . All 60 cases had electrocardiographic evidence of infarction, this being a necessary criterion for inclusion in our series, whereas in 3 of the 60 cases there was no vectorcardiographic evidence of infarction.

TABLE I

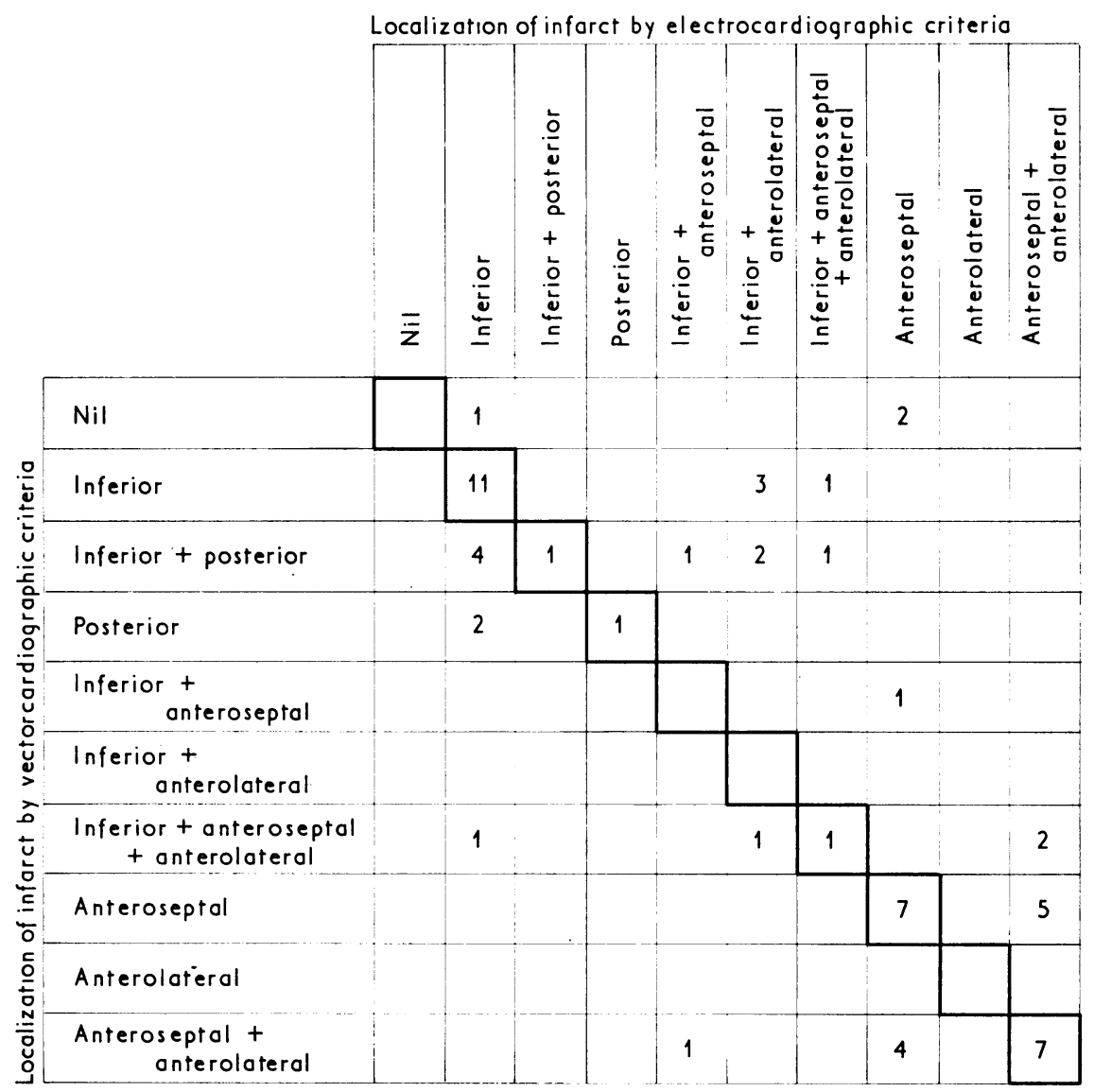


TABLE 2 Bundle-branch block, recent myocardial infarction

\begin{tabular}{|c|c|c|}
\hline No. of cases & Electrocardiographic diagnosis & Vectorcardiographic diagnosis \\
\hline $\mathbf{I}$ & Right bundle-branch block + anterolateral infarct & Right bundle-branch block \\
\hline 2 & $\begin{array}{l}\text { Right bundle-branch block + anteroseptal infarct } \\
\text { + anterolateral infarct }\end{array}$ & $\begin{array}{l}\text { Right bundle-branch block }+ \text { anteroseptal infarct } \\
+ \text { anterolateral infarct }\end{array}$ \\
\hline$I^{\star}$ & Right bundle-branch block & Right bundle-branch block + posterior infarct \\
\hline I & Right bundle-branch block + inferior infarct & $\begin{array}{l}\text { Right bundle-branch block + posterior infarct } \\
+ \text { inferior infarct }\end{array}$ \\
\hline $\begin{array}{l}3 \\
\mathbf{I}\end{array}$ & $\begin{array}{l}\text { Left bundle-branch block } \\
\text { Left bundle-branch block }+ \text { inferior infarct }\end{array}$ & $\begin{array}{l}\text { Left bundle-branch block + anteroseptal infarct } \\
\text { Left bundle-branch block + inferior infarct } \\
\text { + anteroseptal infarct }\end{array}$ \\
\hline
\end{tabular}

* This patient had a previous anteroseptal infarct and is also included in Table 3.

Inferior infarction In this group the QRS loops of the vectorcardiogram frequently indicated evidence of inferior infarction when scalar evidence was restricted to $S T$ and $T$ changes but these scalar changes were never preceded by vectorial QRS abnormalities. When significant vector and scalar QRS changes did not evolve simultaneously, the vectorial criteria were usually fulfilled earlier. Even when criteria for involvement of other areas of the left ventricle were satisfied this observation still held after the acute infarction. Where there was evidence of both old and recent infarction we had no evidence that either the electrocardiogram or vectorcardiogram was superior.

Anteroseptal infarction Again we found that, after an acute infarction, significant abnormalities in the QRS loop of the vectorcardiogram could evolve while scalar evidence of infarction was limited to $S T$ and $T$ changes but these scalar features were never preceded by the vectorial changes. In this group vector and scalar QRS abnormalities evolved simultaneously.

Anterolateral infarction Anterolateral infarction was only diagnosed in conjunction with anteroseptal infarction or, less frequently, inferior infarction, except for I patient with right bundle-branch and scalar evidence of an anterolateral infarct.

Again, as with anteroseptal infarction, the vectorcardiogram might show abnormalities of the QRS loop while scalar evidence of infarction was restricted to ST and T changes. When both the electrocardiogram and vectorcardiogram showed QRS abnormalities these sometimes appeared first

TABLE 3 Patients with past and present episodes of myocardial infarction

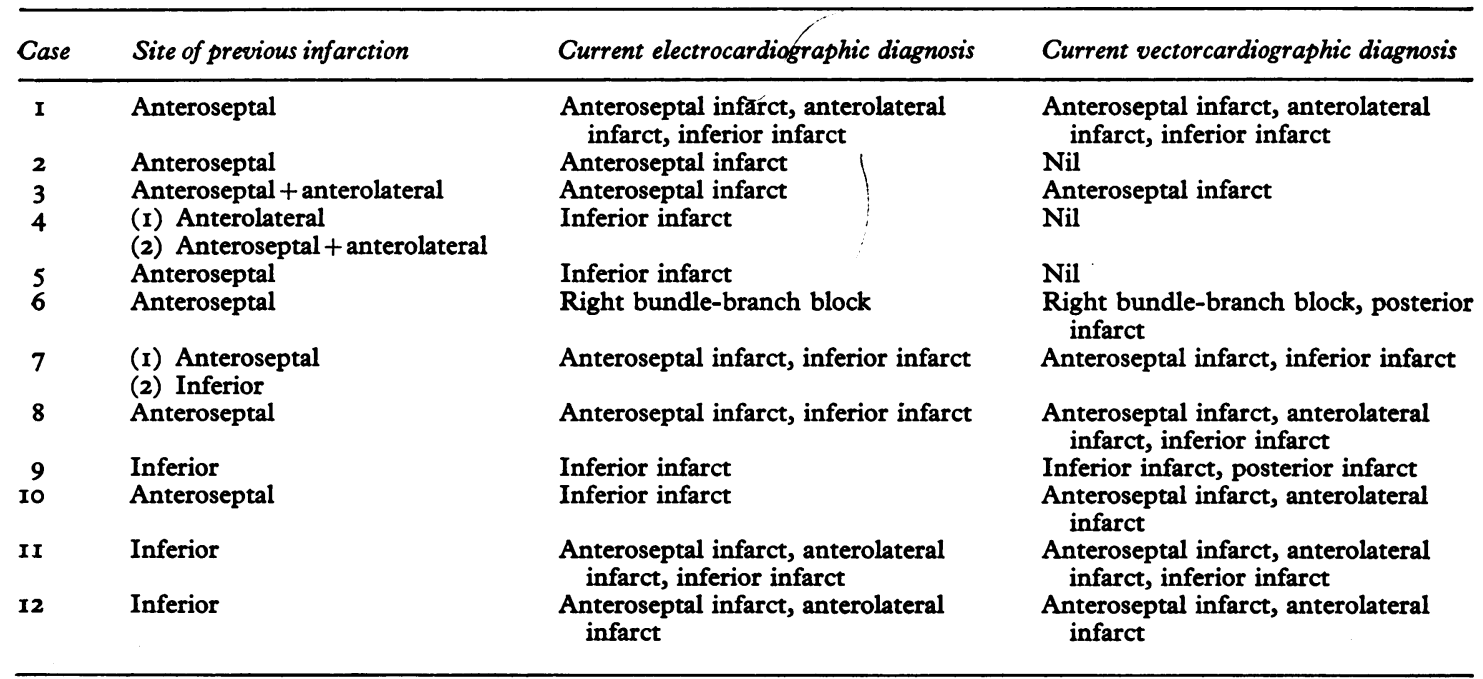


in the vectorcardiogram but only in one case did they appear first in the electrocardiogram.

Posterior infarction Posterior infarction was usually suspected in association with inferior infarction and there was a poor correlation between the elsctrocardiogram and the vectorcardiogram. In the one case where posterior infarction was diagnosed in both the electrocardiogram and vectorcardiogram the scalar abnormalities appeared earlier.

\section{Patients with bundle-branch block and in- farction}

In cases with bundle-branch block which fulfilled the cardiographic criteria of infarction there was seldom agreement between the electrocardiogram and vectorcardiogram (Table 2 ).

\section{Patients with old and acute episodes of in- farction}

In these 12 cases there was agreement between electrocardiogram and vectorcardiogram in location of the fresh infarction in only 5 of them (Table 3). Again the electrocardiogram had the advantage of demonstrating ST and T changes, whereas in some cases the vectorcardiogram showed QRS loop evidence of infarction when only the ST and $T$ changes were present in the electrocardiogram.

\section{Discussion}

Although our study was a purely cardiographic one without necropsy confirmation, all our patients had classical clinical episodes of infarction with biochemical and scalar electrocardiographic confirmation. As we have already shown there is a wide choice of criteria for the diagnosis and localization of infarction and this should constantly be borne in mind in routine interpretation of the electrocardiogram and vectorcardiogram. The striking result we obtained is that in more than half the cases there was disagreement between the electrocardiogram and vectorcardiogram in the localization of infarction and this despite the fact that the scalar and vector criteria for diagnosis and localization of infarction selected by us were widely accepted. In clinical practice this may not be too important but it does emphasize the empiricism of electrocardiography and the continued need to strive for more precise and quantitative criteria for diagnosis and localization of infarction and the need to obtain clinicopathological correlation.

Studies of serial changes in the vectorcardiogram during the clinical episode of acute infarction and comparison with the scalar electrocardiogram have been relatively limited. Karni (1956) studied the evolutionary changes in the spatial $\mathrm{T}$ loop during a period of three weeks after the onset of symptoms. Our investigation has allowed us to make an evaluation of the relative usefulness of scalar and vector electrocardiography in detecting significant early changes during the phase of ventricular depolarization. Benchimol and Barreto (1969) made brief reference to a similar comparison during a study of the evolutionary changes in the vectorcardiogram restricted to acute inferior infarction and their findings and ours are in agreement. We have compared such changes in the vectorcardiogram and the electrocardiogram after an acute inferior, anteroseptal, and combined anteroseptal and anterolateral infarction. The significant finding is that the earliest evidence of infarction in the scalar electrocardiogram is often restricted to $S T$ and $T$ changes though in the corresponding vectorcardiograms evidence of infarction may be present in the QRS loop. In those cases in which both electrocardiogram and vectorcardiogram show QRS abnormalities, these can frequently be detected earlier in the vectorcardiogram whereas the converse finding is rare. If the vectorcardiogram is to play a significant part in the early detection of acute infarction, it is likely to be in regard to its superiority over the electrocardiogram in demonstrating QRS abnormalities.

This work was assisted by a grant from the British Heart Foundation.

\section{References}

Abramson, H. (1963). The frontal plane QRS loop in the normal heart and in diaphragmatic myocardial infarction. Canadian Medical Association fournal, 89, 47.

Benchimol, A., and Barreto, E. C. (1969). Serial vectorcardiograms with the Frank system in patients with acute inferior wall myocardial infarction. Fournal of Electrocardiology, 2, 159.

Burch, G. E., Horan, L., Abildskov, J. A., and Cronvich, J. A. (1955). A study of the spatial vectorcardiogram in subjects with posterior myocardial infarction. Circulation, 12, 418 .

Burch, G. E., Horan, L., and Cronvich, J. A. (1956). A study of the spatial vectorcardiogram in subjects with anterior myocardial infarction. Circulation, 13, 360.

Burch, G. E., Horan, L. G., Ziskind, J., and Cronvich, J. A. (1958). A correlative study of postmortem electrocardiographic and spatial vectorcardiographic data in myocardial infarction. Circulation, 18, 325.

Chou, T., Helm, R. A., and Lach, R. (1964). The significance of a wide TsÊ loop. Circulation, 30, 400 .

Cosby, R. S., Talbot, J. C., Levinson, D. C., and Mayo, M. (1955). The vector-electrocardiogram in acute coronary insufficiency and in acute myocardial infarction. American Heart fournal, 49, 896.

Doucet, P., Walsh, T. J., and Massie, E. (1966). A vectorcardiographic and electrocardiographic study of left bundle branch block with myocardial infarction. American fournal of Cardiology, 17, 17 I. 
Eddleman, E. E., and Pipberger, H. V. (197I). Computer analysis of the orthogonal electrocardiogram and vectorcardiogram in 1,002 patients with myocardial infarction. American Heart fournal, 81, 608.

Elek, S. R., Allenstein, B. J., Griffith, G. C., Cosby, R. S., and Levinson, D. C. (I954). A correlation of the spatial vectorcardiogram with right ventricular hypertrophy. American Heart fournal, 47, 369.

Elliot, B. A., and Wilkinson, J. H. (I96I). Serum ' $\alpha$-hydroxybutyric dehydrogenase' in myocardial infarction and in liver disease. Lancet, 1, 698.

Frank, E. (1956). An accurate, clinically practical system for spatial vectorcardiography. Circulation, 13, 737.

Gunnar, R. M., Pietras, R. J., Blackaller, J., Dadmun, S. E., Szanto, P. B., and Tobin, J. R., Jr. (1967). Correlation of vectorcardiographic criteria for myocardial infarction with autopsy findings. Circulation, 35, 158.

Hoffman, I., and Schack, J. A. (1956). The T wave in bundle branch system block: the significance of the angle formed by the terminal portion of QRS and the mean $T$ vector. American Heart fournal, 52, 862.

Hoffman, I., Taymor, R. C., and Gootnick, A. (1964). Vectorcardiographic residua of inferior infarction. 78 cases studied with the Frank system. Circulation, 29, 562.

Hoffman, I., Taymor, R. C., Morris, M. H., and Kittell, I. (1965). Quantitative criteria for the diagnosis of dorsal infarction using the Frank vectorcardiogram. American Heart fournal, 70, 295.

Howitt, G., and Lawrie, T. D. V. (1960). Vectorcardiography in myocardial infarction. British Heart fournal, 22, 6I.

Hugenholtz, P. G., Forkner, C. E., and Levine, H. D. (196ra). A clinical appraisal of the vectorcardiogram in myocardial infarction. II. The Frank system. Circulation, 24, 825.

Hugenholtz, P. G., Ryan, T. J., Worner, T., and Levine, H. D. (1963). Recognition of anterior wall infarction in patients with left ventricular hypertrophy. Circulation, 27, 386.

Hugenholtz, P. G., Whipple, G. H., and Levine, H. D. (196Ib). A clinical appraisal of the vectorcardiogram in myocardial infarction. I. The cube system. Circulation, 24, 808.

Jacobson, E. D., Rush, S., Zinberg, S., and Abildskov, J. A. (1959). The effect of infarction on magnitude and orientation of electrical events in the heart. American Heart fournal, 58, 863 .

Karlen, W. S., Wolff, L., and Young, E. (1956). The vectorcardiogram in anterior myocardial infarction. III. American Heart fournal, 52, 45.

Karni, H. (1956). The TsE-loop in myocardial lesions. A preliminary report. American Heart fournal, 52, 867.

Milnor, W. R. (1957). Electrocardiogram and vectorcardiogram in right ventricular hypertrophy and right bundlebranch block. Circulation, 16, 348 .

Milnor, W. R., Genecin, A., Talbot, S. A., and Newman, E. V. (1951). Vectorcardiographic study of ' $Q_{3}$ ' deflection in cases of myocardial infarction and in normal subjects. Bulletin of the fohns Hopkins Hospital, 89, 281 .

Myers, G. B., Klein, H. A., and Hiratzka, T. (1948a). Correlation of electrocardiographic and pathologic findings in large anterolateral infarcts. American Heart fournal, 36, 838 .
Myers, G. B., Klein, H. A., and Hiratzka, T. (1949a). Correlation of electrocardiographic and pathologic findings in posterior infarction. American Heart fournal, 38, 547.

Myers, G. B., Klein, H. A., and Hiratzka, T. (r949b). Correlation of electrocardiographic and pathologic findings in posterolateral infarction. American Heart fournal, 38, 837 .

Myers, G. B., Klein, H. A., and Stofer, B. E. (1948b). Correlation of electrocardiographic and pathologic findings in anteroseptal infarction. American Heart fournal, 36, 535 .

Reitman, S., and Frankel, S. (1957). A colorimetric method for the determination of serum glutamic oxaloacetic and glutamic pyruvic transaminases. American fournal of Clinical Pathology, 28, 56.

Rothfield, E. L., Bernstein, A., Wachtel, F. W., and Karlen, W. S. (196I). The vectorcardiogram in direct posterior wall myocardial infarction. American fournal of Cardiology, $7,496$.

Rothfield, E. L., Wachtel, F. W., Karlen, W. S., and Bernstein, A. (1959). Vectorcardiographic analysis of myocardial infarction characterized by tall $\mathbf{R}$ waves in right praecordial leads. Circulation, 20, 759.

Sano, T., Oshima, H., Shiina, S., Shimamoto, T., Nishikawa, S., Negiski, T., and Maeda, K. (I960). The T vector loop in arteriosclerosis. Respiration and Circulation (fapan), 8, 131.

Scherlis, L., and Grishman, A. (I95I). Spatial vectorcardiography: myocardial infarction. V. American Heart fournal, 42, 24.

Simonson, E., Tuna, N., Okamoto, N., and Toshima, H. (1966). Diagnostic accuracy of the vectorcardiogram and electrocardiogram. A co-operative study. American Fournal of Cardiology, 17, 829.

Sodi-Pallares, D. (1956). New Bases of Electrocardiography. C. V. Mosby, St. Louis.

Tranchesi, J., Teixeira, V., Ebaid, M., Boccalandro, I., Bocanegra, J., and Pileggi, F. (196I). The vectorcardiogram in dorsal or posterior myocardial infarction. American fournal of Cardiology, 7, 505 .

Walsh, T. J., Tiongson, P. M., Stoddard, E. A., and Massie, E. (1962). Vectorcardiographic QRSsE-Loop findings in inferoposterior myocardial infarction. American Heart Fournal, 63, 516 .

Wolff, L. (1955). The vectorcardiographic diagnosis of myocardial infarction. Diseases of the Chest, 27, 263.

Wolff, L., Wolff, R., Samartzis, M. D., Mazzoleni, A., Soffe, A. M., Reiner, L., and Mutsuoka, S. (196I). Vectorcardiographic diagnosis. A correlation with autopsy findings in 167 cases. Circulation, 23, 86r.

World Health Organization (1959). Hypertension and coronary heart disease: classification and criteria for epidemiological studies. World Health Organization. Technical Report Series, No. 168.

Young, E., Wolff, L., and Chatfield, J. (1956a). The normal vectorcardiogram. I. American Heart fournal, 51, 713.

Young, E., Wolff, L., and Karlen, W. (1956b). The vectorcardiogram in inferior myocardial infarction. IV. American Heart fournal, 52, 232.

Requests for reprints to Professor K. G. Lowe, Department of Medicine, University of Dundee, Dundee DDI $4 \mathrm{HN}$. 